\title{
A EDUCAÇÃO SOCIAL COMO EIXO DE TRABALHO NAS MEDIDAS SOCIOEDUCATIVAS DE SEMILIBERDADE
}

\author{
SOCIAL EDUCATION FOR JUVENILE OFFENDERS
}

\author{
(D) Natália Cardoso Marra \\ Doutora em Ciências Sociais, PUC Minas. \\ Belo Horizonte, Minas Gerais, Brasil. \\ natimarra@yahoo.com.br
}

\begin{abstract}
Resumo: Os adolescentes que cometem atos infracionais cumprem medidas socioeducativas. Estas têm a finalidade de orientá-los e responsabilizá-los, apresentando outras oportunidades para a vida. A escola é um instrumento fundamental para que a medida socioeducativa gere os efeitos esperados. Assim, esta pesquisa visa discutir como uma escola que recebe vários jovens em cumprimento de medida de semiliberdade lida com os mesmos, tendo em vista a gestão escolar e a relação estabelecida entre os adolescentes e a instituição de ensino. Para a obtenção dos resultados analisados foram feitas entrevistas, visitas a campo e o acompanhamento de medidas socioeducativas de semiliberdade.
\end{abstract}

Palavras-chave: Medida socioeducativa de semiliberdade. Educação social. Adolescente infrator. Inclusão escolar.

Abstract: Adolescents who commit offenses comply with socio-educational measures. These are intended to guide and hold them accountable, presenting other opportunities for life. The school is a fundamental instrument for the socio-educational measure to generate the expected effects. Thus, this research aims to discuss how a school that receives several young people in compliance with semi-freedom measure deals with them, in view of school management and the relationship established between adolescents and the educational institution. In order to obtain the analyzed results, interviews, field visits and the monitoring of socio-educational measures of freedom were carried out.

Keywords: Socio-educational measure of semiliberty. Social education. Adolescent. School inclusion.

\section{Para citar - ABNT NBR 6023:2018}

MARRA, Natália Cardoso. A educação social como eixo de trabalho nas medidas socioeducativas de semiliberdade. Cadernos de Pós-graduação, São Paulo, v. 19, n. 2, p. 4-14, jul./dez. 2020. Disponível em: https://doi.org/10.5585/cpg.v19n2.14728.

\section{Introdução}

A cada dia que passa cresce o número de adolescentes envolvidos com a criminalidade. Em razão da maioridade penal no Brasil ser adquirida aos dezoito anos, aqueles que cometem atos infracionais antes de atingir referida idade cumprem medidas socioeducativas (MSE).

As medidas socioeducativas estão previstas no art. 112 do Estatuto da Criança e do Adolescente - ECA (BRASIL, 1990) e estão dispostas da seguinte forma: 
Art. 112: Verificada a prática de ato infracional, a autoridade competente poderá aplicar ao adolescente as seguintes medidas:

I - advertência;

II - obrigação de reparar o dano;

III - prestação de serviços à comunidade;

IV - liberdade assistida;

$\mathrm{V}$ - inserção em regime de semi-liberdade;

VI - internação em estabelecimento educacional;

VII - qualquer uma das previstas no art. 101, I a VI.

$\int 1^{\circ} \mathrm{A}$ medida aplicada ao adolescente levará em conta a sua capacidade de cumpri-la, as circunstâncias e a gravidade da infração.

$\int 2^{\circ} \mathrm{Em}$ hipótese alguma e sob pretexto algum, será admitida a prestação de trabalho forçado.

$\int 3^{\circ}$ Os adolescentes portadores de doença ou deficiência mental receberão tratamento individual e especializado, em local adequado às suas condições.

$\mathrm{O}$ art. 101 do ECA, mencionado no inciso VII acima transcrito, afirma que cabe medida protetiva de matrícula e frequência obrigatórias em estabelecimento oficial de ensino fundamental. Referida previsão apoia o cumprimento do direito social à educação, disposto no art. $6^{\circ}$ da Constituição Federal de 1988, reforçado pelo art. 53 do ECA que diz: "a criança e o adolescente têm direito à educação, visando ao pleno desenvolvimento de sua pessoa, preparo para o exercício da cidadania e qualificação para o trabalho".

O destaque dado à educação deriva do fato do jovem se encontrar em processo de formação, seja social, física ou cognitiva. Conforme Piaget (1986), a maturação é considerada como fator básico de amadurecimento interno do sistema nervoso e desempenha um papel indispensável. Entretanto este fator por si só é insuficiente. Assim devem ser agregados, equilibradamente, fatores de aprendizagem, como os transmitidos socialmente em estabelecimentos educacionais e as experiências vividas. Desta maneira, é fundamental a garantia de acesso à educação para a devida formação da criança e do adolescente, tendo em vista a redução do número de jovens envolvidos com a criminalidade.

Buscando efetivar os dispositivos constitucionais e do ECA já citados, as medidas socioeducativas se fundamentam na escolarização, profissionalização e responsabilização. Desta forma, as medidas que provocam restrição da liberdade, como a de semiliberdade e a de internação, devem encaminhar os adolescentes a instituições escolares ou manter uma instituição internamente.

Os jovens que estão em cumprimento de semiliberdade devem ser então, matriculados em escolas da sua comunidade ou próximas à Unidade onde estão acautelados. Na região de Venda Nova, em Belo Horizonte, são encontradas cinco Unidades de Semiliberdade, por isso, as escolas situadas nesse local recebem muitos adolescentes e jovens infratores, com idade entre 12 e 21 anos, normalmente apresentando defasagem escolar.

O objetivo da presente pesquisa é discutir como uma escola que recebe vários jovens em cumprimento de medida de semiliberdade lida com os mesmos, tendo em vista a gestão escolar e 
a relação estabelecida entre os adolescentes e a instituição de ensino. Assim, para este estudo foi analisada uma escola da região de Venda Nova, Belo Horizonte, que recebe diversos jovens que estão cumprindo MSE, tanto no turno diurno quanto no noturno.

Para a pesquisa foram realizadas visitas técnicas à escola e às Unidades de Semiliberdade que possuem adolescentes matriculados na escola objeto do estudo. Estas visitas tinham como objetivo verificar a estrutura dos locais, conhecer os profissionais (formação, quantidade) que neles atuam, verificar o uso dos espaços e a dinâmica de funcionamento.

Foi feito um levantamento da rotina destes adolescentes no cumprimento da medida socioeducativa e analisado como a escola se insere no cotidiano dos estudantes e dos técnicos que atuam nas Unidades. A partir deste levantamento foi verificado como estas rotinas refletem no comportamento e no engajamento dos adolescentes na escola. Foram interpretadas também as influências da formação e do vínculo escolar no cumprimento da medida. Para tanto, as equipes técnicas das Unidades Socioeducativas foram entrevistadas e profissionais da escola. As informações obtidas ao longo do trabalho de campo foram analisadas com base em referenciais bibliográficos.

\section{A organização da escola estudada: espaço e gestão escolar}

A escola trabalhada neste artigo está localizada no Bairro Rio Branco em Belo Horizonte, região de Venda Nova. Referida instituição atende a estudantes do primeiro ao nono ano. Os alunos se dividem em dois blocos, cada um com dois andares. Cada bloco tem uma coordenadora responsável.

A escola possui um pequeno estacionamento para professores, porteiro e um guarda municipal, cuja função é zelar pelo patrimônio público.

Durante as aulas os alunos trocam de salas, pois cada professor tem a sua. A circulação é sempre no mesmo bloco, exceto quando se trata das aulas de educação física e de informática, pois essas ocorrem em um espaço à parte.

No intervalo, há música, bolas, dois 'totós' e duas mesas de tênis de mesa disponíveis. Os alunos circulam livremente pela escola, apenas acompanhados pelas professoras e estagiários. $\mathrm{O}$ clima é de harmonia e não foi observada nenhuma situação de violência ou de desacordo. Uma grande quadra coberta e outras duas menores ficam à disposição dos adolescentes. Enquanto isso, as salas de aula ficam trancadas.

A biblioteca é bem equipada e conta com duas funcionárias, além de um computador com acesso à internet para ser usado pelos alunos. Os jovens, durante o intervalo, vão à biblioteca jogar 
jogos e buscar livros (há lista de reserva para livros e de indicações de obras). Professores, principalmente de português, deixam livre um tempo da aula para que os alunos frequentem a biblioteca e segundo a bibliotecária o espaço é muito bem usado e respeitado pelos estudantes.

A estrutura física da instituição é muito bem cuidada e elaborada. As paredes são bem pintadas, o jardim agradável, os banheiros em bom estado de conservação.

Uma das coordenadoras da escola dispõe que não são percebidos problemas relacionados ao uso do espaço escolar, nem mesmo frente à gestão, pois afirma que essa é de fato democrática e envolve os diversos profissionais que atuam na instituição de ensino.

Um dos principais problemas apontados pela coordenação foi a dificuldade de envolver o aluno com o processo educativo. Ainda que haja problemas de comportamento durante as aulas, conforme foi observado durante a pesquisa, um enfrentamento dos professores é o pouco caso dos alunos frente às tarefas de casa, como deveres e trabalhos. Esse pouco caso é reflexo, também, do baixo envolvimento das famílias, que para a coordenação, apesar de frequentarem a escola sempre que convocadas, deixam a situação como está, não se mostram descontentes com as baixas notas ou mau comportamento dos filhos.

Os próprios professores ficam desmotivados com o baixo rendimento dos estudantes e saem de licença com frequência. A questão é que não é fácil encontrar substitutos, principalmente durante o período eleitoral, quando é vedada a contratação de professores. Quando não há um profissional para acompanhar as aulas, os alunos ficam sem atividades, o que gera um ciclo vicioso provocando a desmotivação desses.

Outro problema apontado pela coordenação é a grande demanda de trabalho, agravada pela relação estabelecida entre os professores e a gestão. Os professores demandam da coordenação a todo o momento, não investem muito tempo na compreensão ou diálogo com o aluno, logo transferem o problema. Já os estudantes parecem gostar desse posicionamento dos professores, pois quando estão na coordenação estão fora de sala e não assistem às aulas.

Quando ocorrem problemas disciplinares, primeiro é feita uma intervenção com o estudante. Caso essa não surta os efeitos esperados os pais ou responsáveis são acionados. Em algumas situações, o guarda municipal é chamado para garantir a segurança de professores e coordenadores, caso o aluno extrapole os limites da boa convivência.

Como a escola recebe muitos alunos que cumprem medida socioeducativa de semiliberdade é recorrente a repreensão destes pelo guarda municipal, pela coordenação e pelos professores, que os acompanham de perto. 


\title{
A relação entre a educação e o cumprimento da medida socioeducativa de semiliberdade
}

A medida socioeducativa - MSE - de semiliberdade consiste em uma medida restritiva que tem como objetivo lidar com o adolescente que comete atos infracionais, possibilitando a sua orientação e ressocialização.

Os eixos que orientam a citada MSE são o ato infracional, a família, a saúde, as relações sociais, a escolarização e a profissionalização, sendo esses dois últimos os mais cobrados pelo Poder Judiciário, já que apresentam dados estatísticos mais práticos como frequência escolar, notas, comprovantes de matrícula e certificados de conclusão de cursos.

O eixo família deve ser diretamente relacionado aos de escolarização e de profissionalização, pois o adolescente não cumprirá MSE para sempre e assim, a família precisará acompanhá-lo após o desligamento da medida. No entanto, a mesma realidade familiar enfrentada pelos profissionais da escola estudada é enfrentada pelos que atuam na execução da semiliberdade, um abandono e um desinteresse da família pelos adolescentes.

A responsabilidade socialmente atribuída à família segundo Ribeiro (2006):

\begin{abstract}
parece sucumbir diante das precárias condições com que tem que sobreviver (extrema pobreza, mudança freqüente de parceiros, relações violentas em seu interior com reações de fuga) e conduzir a educação de seus filhos, levando-a a contradições no exercício da socialização e controle dos mesmos, não lhe permitindo ser capaz de apontar os limites necessários à convivência em sociedade. Se bem que não se possa considerá-la como a única, nem a principal responsável pelo envolvimento dos jovens no mundo da infração, a família, em alguns casos, representa uma influência negativa, potencializada pela ação de uma conjuntura social em que a miséria, o narcotráfico, a lógica da cultura do consumismo, a influência perversa da comunidade (onde é comum o uso de drogas, de armas e de assassinatos), desencadeiam mecanismos subjetivos e de relacionamentos em que as experiências de violência extrema passam a ser percebidas e vividas como algo rotineiro e banal. (RIBEIRO, 2006, p. 162).
\end{abstract}

O apoio da família é primordial para o cumprimento dos eixos da MSE e para o retorno do jovem das saídas externas autorizadas.

A exigência mínima de frequência escolar para o jovem em cumprimento de MSE é de $75 \%$. Esse é um dado claro, mas há imensa dificuldade por parte dos adolescentes de atingir essa meta. Essa dificuldade demonstra o frágil enlace que existe entre os estudantes e a escola.

Ao longo do cumprimento da medida de semiliberdade o adolescente circula externamente com autorização da equipe técnica e tem horário para retornar à Unidade Socioeducativa. As liberações para a saída sempre se dão em razão de um encaminhamento, como ir à escola, a uma atividade de lazer ou a um acompanhamento médico. Caso o horário estabelecido para retorno seja descumprido, é aplicada uma comissão disciplinar que sanciona o jovem, impedindo-o de sair em outra oportunidade (exceto para ir ao médico ou à escola). O prazo máximo que um adolescente 
pode atrasar é de $24 \mathrm{~h} s$. Ultrapassado esse prazo, só há retorno com intervenção judicial e é expedido um mandado de busca e apreensão.

A volta para a Unidade é uma escolha, afinal o adolescente sai da Unidade para fazer os encaminhamentos e pode optar por não retornar e evadir, o que ocorre frequentemente. Quando isso acontece há o abandono da escola, pois o jovem evadido não comparece à instituição de ensino com medo de ser apreendido por mandado de busca e apreensão.

O perfil dos adolescentes em cumprimento de MSE se compõe de pessoas que abandonaram a escola e já apresentam muita defasagem. A grande maioria dos acautelados cursa a modalidade Educação de Jovens e Adultos - EJA. Os adolescentes que não se encaixam na EJA ficam muito incomodados e constrangidos em assistir às aulas junto a outros estudantes muito mais novos. Os vínculos escolares, nestes casos, foram rompidos quando o adolescente ainda tinha um maior convívio com a família, ou seja, antes de ter sua liberdade restrita.

Pode-se observar, que quando o adolescente inicia a sua trajetória infracional a escola perde espaço na sua rotina, pois deixa de representar uma perspectiva de futuro melhor, passando a ser um empecilho para o exercício da prática de atos infracionais, afinal, 'toma tempo de mais'.

Dessa maneira, o trabalho da escola com um adolescente infrator é ainda mais difícil do que com outros devido a diversos fatores: os laços foram rompidos, a família se encontra desmotivada, deve-se competir com a tentação da vida no crime, a defasagem escolar é marcante.

Quando o aluno está em cumprimento de medida de semiliberdade outros problemas ainda são deflagrados. O adolescente tem poucas oportunidades de ir pra rua fazer o que deseja, já que só sai mediante autorização da equipe. Como a escolarização é um eixo obrigatório da MSE, as liberações para frequentar instituições de ensino são quase certas. Tendo em vista as restrições para a circulação, o adolescente acaba usando das saídas que deveriam atender à escolarização para desviarem de percurso e ir fazer o que querem (passear, ver amigos, encontrar com as namoradas). $\mathrm{O}$ pedagogo da Unidade, ao verificar a frequência escolar sempre se depara com baixos índices e os jovens se justificam dizendo que "tinham que fazer os seus corres".

Além da baixa frequência dos alunos a escola precisa lidar com as evasões escolares. Em alguns casos, os infratores são encaminhados a centros de internação provisória e deixam de frequentar a escola formal, bem como evadem ou fogem da Unidade e também abandonam os estudos.

Essas muitas interrupções no percurso escolar acarretam uma maior dificuldade de aproximação da instituição de ensino com os alunos, além de deixarem a formação escolar descontínua. 
Diante de tantos problemas, a realização da matrícula escolar dos jovens pela equipe técnica das Unidades Socioeducativas é complicada. Muitas escolas da região de Venda Nova têm resistência em receber os infratores que cumprem semiliberdade e é necessário requerer uma intervenção da Regional da Prefeitura. Essa intervenção é boa por garantir a matrícula, mas faz com que a relação escola/estudante já comece viciada.

Os percalços são muitos, mas cabe à escola atender aos dispositivos constitucionais que garantem o acesso à educação, especialmente quando se trata de alunos em situação de grande vulnerabilidade social.

A escola trabalhada já teve muitos problemas com adolescentes em cumprimento de semiliberdade. Aconteceram casos de violência frente ao Guarda Municipal, uso de droga, pichação e desrespeito. No entanto, a escola tem aprendido a lidar com essa situação, pois não tem como rejeitar as matrículas dos infratores quando a Regional intervém.

Um caso de sucesso foi influenciado por atitudes da escola em questão foi a maneira escolhida por esta instituição ao tratar os de desvios de um aluno. Esse estudante passou por abrigos desde antes de completar doze anos de idade e cumpria medida socioeducativa há quase dois anos. No entanto o cumprimento se dava todo permeado por evasões e novos atos infracionais, até que a escola conseguiu estabelecer um vínculo que mostrou ao adolescente que ele era mais do que um infrator, mas uma pessoa talentosa.

Era frequente o encaminhamento do adolescente à diretoria e os técnicos da Unidade eram sempre chamados a comparecer à escola para auxiliarem em alguma intervenção com o estudante. Certa vez a pedagoga e a advogada da Unidade foram chamadas à diretoria da escola porque determinado estudante, oriundo da semiliberdade, estava com cheiro de cigarro. Em reunião com a coordenação foi explicado um pouco da trajetória do adolescente e o tanto que a presença dele na escola era fundamental. A partir disso, a relação entre a escola e o estudante mudou.

Poucos dias após esta reunião o referido adolescente foi flagrado matando aula de inglês na quadra da escola. Novamente representantes da Unidade Socioeducativa compareceram à escola. O assunto, inicialmente tratado como um absurdo, após breve conversa, passou a ser interpretado como um grande avanço: o aluno não evadiu da escola, estava apenas dentro de outro espaço escolar com o qual se identificava mais.

$\mathrm{Na}$ visão da pedagoga e da advogada da Unidade esse episódio foi marcante para demonstrar o reposicionamento do adolescente frente à instituição escolar. Ao ser transmitida para a coordenação esta forma de ver a situação, foi proposto ao estudante participar de um show de talentos na escola, pois ele tinha um lado musical bem desenvolvido, cantando Rap cultural, sem uma linguagem violenta, compreendida como imprópria para o ambiente educacional. 
Em outra ocasião citado aluno desenhou cenas obcenas em toda a carteira escolar. A pedagoga da semiliberdade foi até a instituição de ensino esperando pelo pior: possível expulsão ou suspensão por ter sido esta a gota d'água que restava de tolerância. Mas ao contrário do esperado, os professores, diretores e coordenadores propuseram ao aluno a realização de um grafite em um muro da escola.

Surpresos, aluno e pedagoga da Unidade saíram da sala da direção pela derradeira vez, pois não houve mais transgressões por parte do jovem. A partir dessa intervenção foi possível o desligamento da medida socioeducativa.

Essa atitude, de ouvir o estudante, tentando compreendê-lo e oferecendo oportunidades fez toda a diferença e retrata a relevância da escola para a formação da juventude.

Ainda que esse seja um simples caso de sucesso, outros podem ocorrer. A proposta de trabalho da educação social é também uma estratégia capaz de gerar bons resultados para além de uns poucos casos isolados como o mencionado. A escola estudada, assim como outras, é um espaço que pode adotar essa metodologia de ação e possibilitar a inclusão social agregada à escolarização dos vários alunos em cumprimento de MSE que nela estão matriculados.

\section{A proposta da educação social como forma de envolver o aluno}

Ribeiro (2006) tece alguns elementos que permitem uma discussão, ainda inicial, sobre a realidade e as concepções de exclusão/inclusão e educação social, com o fim de revelar ideologias e interesses que as informam. A autora formula a hipótese de que existe uma disputa entre projetos sociais e educacionais contraditórios, resultando, daí, estratégias de combate à exclusão e promotoras de inclusão, encarnadas em concepções e práticas de educação social, como resposta às demandas de políticas sociais públicas provenientes das populações de crianças e jovens em situação de vulnerabilidade.

A educação social existe para tratar da exclusão social. Ocorre que o conceito de exclusão é muito impreciso. O contrário da exclusão é a inclusão, o estar dentro, o reingresso à condição da qual foi excluído. Se considerarmos que os processos de exclusão social são inerentes à lógica do modo de produção capitalista, veremos que as políticas de inclusão e/ou inserção social são estratégias para integrar os objetos - os excluídos - ao sistema social que os exclui e, ao mesmo tempo, de manter sob controle as tensões sociais que decorrem do desemprego e da exploração do trabalho, móveis da exclusão social (RIBEIRO, 2006).

Ribeiro (2006) apresenta as seguintes indagações ao afirmar que o conceito de educação social está indissociavelmente vinculado ao de exclusão: que educação oferecer aos milhares de crianças, adolescentes e adultos excluídos da e na escola; do e no emprego; da e na terra; das e nas 
instituições sociais? Seriam os educadores formados por instituições regulares de ensino, dentro dos princípios, objetivos, conteúdos e métodos tradicionalmente direcionados aos incluídos, os mais preparados para educar os que experimentam as situações de exclusão social? Cumpre destacar que o adolescente envolvido com a criminalidade permeia todos esses questionamentos.

O trabalho do educador social está voltado para aqueles que não estão inseridos nas instituições educacionais mais regulares, tais como a família e a escola. A partir desse conceito é interessante ter um programa cujo objetivo seja oferecer aos educadores sociais uma formação direcionada à intervenção no campo da educação não-formal, comprometida com o atendimento de populações e grupos excluídos socialmente (RIBEIRO, 2006).

A educação social pode ser compreendida também sob a ótica da educação popular e os educadores populares são como 'educadores de rua'. Segundo Gadotti (apud Graciani, 2001, p. 13): "A pedagogia do educador social é, de certa forma, uma contrapedagogia que busca instaurar uma nova cultura, a cultura da solidariedade que possa neutralizar a banalização da vida à qual as elites brasileiras se acostumaram". O termo rua é utilizado com a perspectiva de espacialização, identificando o educador social como aquele que desenvolve a sua ação pedagógica entre crianças e adolescentes "em situação de risco pessoal e social, que têm dificuldades de inserção social (...)".

A pedagogia social de rua, proposta por Graciani, exige uma competência técnica para trabalhar com uma realidade que não corresponde ao espaço, ao tempo, aos conteúdos e métodos da escola formal, articulada a um compromisso político com os educandos. Para isso, as práticas pedagógicas do educador social de rua precisam estar orientadas de modo que propiciem o resgate da cidadania dos sujeitos sociais com os quais desenvolve seu trabalho.

Alguns elementos podem ser destacados quando se faz a relação entre os dois conceitos aparentemente separados e autônomos - exclusão e educação social. Poder-se-ia resumir essa relação afirmando que a educação social é uma necessidade que decorre da exclusão social de crianças e jovens.

Diante desse aparato sobre a educação social é possível observar que qualquer instituição de ensino pode adotar essa metodologia a fim de possibilitar uma vinculação mais próxima com os estudantes. Nem todos os alunos estão no mesmo nível de maturação ou de aprendizagem. É importante considerar as peculiaridades de cada pessoa para que ela possa estabelecer um interesse real pela educação, instrumento primordial para o exercício da cidadania e direito fundamental.

A escola, ao propor uma forma diversa de intervenção com o adolescente aplicou, de certa forma, a educação social. Ter profissionais na escola capacitados para o uso de métodos de educação não formal facilita o enlace com a família e com o estudante que passam por situações de exclusão social, mostrando um outro lado da escola. 
O importante é demonstrar a função social que a educação tem de inclusão e de cidadania, tornando os processos de formação mais interessantes e envolventes. Uma escola que envolve a família e o aluno na educação tem resultados melhores e favorece a retirada de jovens da criminalidade, indicando novos caminhos a serem seguidos.

\section{Considerações finais}

A educação é mais que um direito de todos, mas um desafio enfrentado diariamente pelas instituições e profissionais da rede de ensino no Brasil. São inúmeros os percalços enfrentados, que vão desde aspectos estruturais, como a baixa valorização e os escassos recursos, até aos laços fragilizados das famílias e a tentação da vida na criminalidade.

Diante desse cenário, é difícil imaginar um futuro promissor para a sociedade. No entanto, ainda é despertada esperança quando são percebidas ações como a empreendida pela escola estudada e a proposta de adoção da metodologia da educação social.

O modo de lidar com adolescentes é peculiar em razão do momento de vida vivenciado por esses. Assim, o estabelecimento de um diálogo, de ações que propõe torná-los protagonistas e partícipes no processo educacional é capaz de proporcionar um resultado de sucesso.

Esse trabalho teve como meta demonstrar que a educação é um fator primordial para a redução da violência e que por esse motivo é o eixo norteador das medidas socioeducativas. Demonstrada tamanha relevância, por consideração final, resta afirmar que ainda que singelas, existem experiências sendo realizadas e surtindo efeitos positivos, tanto no meio prático como no acadêmico.

Dessa forma, esta pesquisa se encerra pontuando que há uma luz no fim do túnel e há um caminho.

"As terríveis consequências do pensamento negativo são percebidas muito tarde."

Paulo Freire

\section{Referências}

ASSIS, Simone Gonçalves; SOUZA, Edinilsa Ramos. Criando Caim e Abel-Pensando a prevenção da infração juvenil. Ciência \& Saúde Coletiva, 4(1):131-144, 1999. Disponível em: http://www.scielosp.org/pdf/csc/v4n1/7136.pdf. Acesso em: 21 ago. 2018.

BRASIL, Constituição da República Federativa do Brasil. 20 de agosto de 1988.

BRASIL, Estatuto da Criança e do Adolescente. Lei 8069 de 13 de julho de 1990. 
GRACIANI, M.S.S. Pedagogia social de rua. 4. ed. São Paulo: Cortez; Instituto Paulo Freire, 2001.

PIAGET, Jean O nascimento da inteligência na criança Lisboa: Publicações Dom Quixote, 1986. Disponível em: http://materiadeapoioaotcc.pbworks.com/f/Piaget+-+O+Nascimento+da+Intelig\%C3\%AAncia+na+Crian\%C3\%A7a+(DOC-Livro).pdf. Acesso em: 30 ago. 2018.

RIBEIRO, Marlene. Exclusão e Educação Social: conceitos em superfície e fundo. Revista Educação Social, Campinas, vol. 27, n. 94, p. 155-178, jan./abr. 2006 Disponível em: http://www.scielo.br/pdf/\%0D/es/v27n94/a09v27n94.pdf. Acesso em: 21 ago. 2018. 